\title{
Mechanothermal Approach for N-, S-, P-, and B-Doping of Carbon Nanotubes: Methodology and Catalytic Performance in Wet Air Oxidation
}

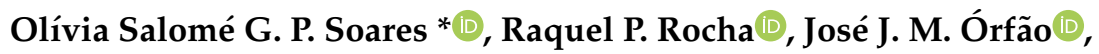 \\ Manuel Fernando R. Pereira $\mathbb{D}^{\mathbb{D}}$ and José L. Figueiredo $\mathbb{D}$ \\ Laboratory of Separation and Reaction Engineering-Laboratory of Catalysis and Materials (LSRE-LCM), \\ Department of Chemical Engineering, Faculty of Engineering, University of Porto, Rua Dr. Roberto Frias, \\ 4200-465 Porto, Portugal; rprocha@fe.up.pt (R.P.R.); jjmo@fe.up.pt (J.J.M.O.); fpereira@fe.up.pt (M.F.R.P.); \\ jlfig@fe.up.pt (J.L.F.) \\ * Correspondence: salome.soares@fe.up.pt; Tel.: +351-22-041-4874
}

Received: 12 April 2019; Accepted: 29 May 2019; Published: 4 June 2019

\begin{abstract}
The texture and the surface chemistry of carbon nanotubes (CNTs) were modified using a solvent-free methodology involving a ball-milling mechanical treatment and thermal treatment under nitrogen in the presence of adequate precursors (melamine, sodium thiosulfate, sodium dihydrogen phosphate, and boric acid) of different heteroatoms ( N, S, P, and B, respectively). The incorporation of these heteroatoms promotes significant changes in the pristine textural and chemical properties. This easy post-doping method allows the introduction of large concentrations of heteroatoms. Their effect on the catalytic activity of the materials was evaluated in the oxidation of oxalic acid by catalytic wet air oxidation (CWAO), as an alternative to the noble metal and rare earth oxide catalysts traditionally used in this process. Improved catalytic activities were obtained using the $\mathrm{N}-$, $\mathrm{P}-$-, and B-doped CNTs in oxalic acid oxidation, while the S-doped CNT sample underperformed in comparison to the pristine material.
\end{abstract}

Keywords: metal-free carbon catalysts; doped carbon nanotubes; heteroatoms; catalytic wet air oxidation; ball milling

\section{Introduction}

Wet air oxidation (WAO) is an interesting process to treat effluents with an organic concentration too high for biological treatments and simultaneously too low for incineration [1,2]. The non-catalytic process requires high temperatures $\left(200-320^{\circ} \mathrm{C}\right)$ and pressures (20-200 bar) to warrant solubility of oxygen and to improve mineralization and degradation rates [3-5]; however, in the last decades, several efforts have been made to decrease these severe operating conditions by introduction of homogeneous or heterogeneous catalysts, mostly based on the use of noble metals and metal oxides [6-8]. Several metal oxides (e.g., $\mathrm{Cu}, \mathrm{Zn}, \mathrm{Mn}, \mathrm{Fe}, \mathrm{Co}$, and $\mathrm{Bi}$ ) and noble metals (e.g., $\mathrm{Ru}, \mathrm{Pt}, \mathrm{Pd}$, and $\mathrm{Rh}$ ) have been investigated for CWAO [9-17]; however, deactivation phenomena are frequent, in particular the leaching of active metals to the liquid phase, which severely limits the efficiency of these heterogeneous catalytic processes. In addition, noble metals and rare earth oxides are facing an increasing price due to their scarcity, and they also cause harmful impacts on the environment. In this context, the use of metal-free carbon materials as catalysts has been recently preferred for many CWAO applications [6,18-25]. The use of metal-free carbon materials can solve the problems associated with metal leaching to the liquid phase $[22,24,26]$. In fact, carbon materials are assuming an increasing role as catalysts in the fields of energy conversion/storage and environmental technologies. Wide 
availability, stability in basic and acidic media, high performance, environmental compatibility, low energy consumption, corrosion resistance, and unique surface properties are some of the advantages that carbon materials offer compared with metal-based catalysts. Moreover, carbon materials present high catalytic activity and reasonable stability in several catalytic processes under mild conditions [27]. Therefore, metal-free catalysts can become more cost-effective and eco-sustainable than metal-based catalysts. Among them, carbon nanotubes (CNTs) have already shown to be a good catalyst alternative for Catalytic Wet Air Oxidation (CWAO); moreover, their performance can be boosted by tuning their surface chemistry $[26,28,29]$.

Due to the ability of carbon atoms to bond with each other (forming linear, planar, and tetrahedral arrangements), the production of carbon materials with distinct properties is possible. Carbon materials used in catalysis have mostly a graphitic structure [30,31]. The unsaturated carbon atoms at the edges of the graphene layers and at basal plane defects are reactive to different compounds containing $\mathrm{O}$, $\mathrm{N}, \mathrm{H}, \mathrm{Cl}, \mathrm{S}, \mathrm{B}, \mathrm{P}$, etc., forming various types of surface functional groups. Such groups may act as promoters or inhibitors, enhancing or diminishing the activity of the carbon catalyst, playing the role of active sites in several reactions, extending their applicability to a wide range of processes [32]. Heteroatoms which are more electronegative (e.g., nitrogen), less electronegative (phosphorus and boron) or with similar electronegativity (e.g., sulphur) as carbon have been incorporated into several carbon materials (CNTs, CNFs, ordered mesoporous carbons, graphene-based materials, and carbon gels) and tested as catalysts in several reactions, for example the oxygen reduction reaction (ORR), catalytic ozonation, or CWAO [32,33].

Heteroatom-doping of carbon materials can be achieved either by in-situ doping during synthesis, or by post-doping in the presence of heteroatom-precursors [34]. Post-doping methods usually involve complex multistep processes and expensive specific equipment as well as severe operating conditions. Mechanochemical treatments have gained notable attention in the nanomaterials research community in the last decade [35]. Ball milling is a promising method for modifying CNTs by adjusting tube lengths, opening closed end caps or doping with heteroatoms. Doping carbon materials by ball milling can become a potential route to produce low-cost materials, avoid the use of solvents and the consequent release of wastes. Ammonium bicarbonate $\left(\mathrm{NH}_{4} \mathrm{HCO}_{3}\right)$ can be used to introduce functional groups like amine or amide on the surface of CNTs by in-situ amino functionalization [36]. Ball milling of graphite with melamine allows to prepare $\mathrm{N}$-doped graphene, facilitating the exfoliation of the resultant small particles into few-layer N-doped graphene nanosheets under ultrasonication [37]. Melamine also allows the introduction of significant amounts of nitrogen on the surface of CNTs by a solvent-free method using ball milling [38]. In addition to $\mathrm{N}$-incorporation into carbon materials, the ball milling approach has also been investigated to incorporate other heteroatoms $[39,40]$. Dry ball milling of graphite in the presence of $\mathrm{H}_{2}, \mathrm{CO}_{2}, \mathrm{SO}_{3}$, or $\mathrm{CO}_{2} / \mathrm{SO}_{3}$ mixture has been used to efficiently prepare edge-selectively functionalized graphene nanoplatelets with different functional groups (hydrogen-, carboxylic acid-, sulphonic acid-, and carboxylic acid/sulphonic acid) [41]. Sulphurized graphene nanoplatelets were produced by similar dry ball milling of graphite using sulphur (S8) [42]. CNTs were also mixed with boron carbide powder [43] and with red phosphorus [44] by a dry ball milling technique.

In the present work, we extend a recently developed solvent-free post-doping methodology involving a mechanical step under ball-milling and subsequent thermal treatment under $\mathrm{N}_{2}$ [38] to the incorporation of $\mathrm{B}, \mathrm{P}$, or $\mathrm{S}$ onto the surface of $\mathrm{CNT}$, using easily available precursors such as sodium thiosulfate, sodium dihydrogen phosphate, and boric acid, which to the best of our knowledge have never been tested as heteroatom-precursors for doping of commercial CNTs. N-doped carbon samples have already demonstrated to be promising metal-free catalysts for CWAO [45], and here we also report for the first time that the obtained B, P, or S-doped CNTs prepared by this easy mechanothermal approach can be used as efficient catalysts in the degradation of organic compounds by Catalytic Wet Air Oxidation (CWAO). To the best of our knowledge, there are no previous works in the literature reporting on the use of $\mathrm{B}$ or P-doped CNTs as metal-free catalysts for CWAO, most of the applications of these heteroatoms being in the field of renewable energy. 


\section{Materials and Methods}

\subsection{Materials}

Commercial multiwalled carbon nanotubes NC3100 (Nanocyl ${ }^{\mathrm{TM}}$, Sambreville, Belgium) were used as raw material (CNT-O). Pristine CNT-O were ball milled with different solid precursors in grinding jars using zirconium oxide balls in a Retsch MM200 equipment (Retsch GmbH, Haan, Germany) without any gas flow using the milling conditions determined in a previous work [46]. A constant vibration frequency of 15 vibrations/s during $4 \mathrm{~h}$ was applied for all ball milled materials. Sodium thiosulfate was evaluated in the S-doping and sodium dihydrogen phosphate and boric acid were tested as $\mathrm{P}$ and $\mathrm{B}$ precursors, respectively. $\mathrm{N}$-doping was performed using melamine, repeating a previously reported methodology [38]. The doped samples were obtained by mixing $0.6 \mathrm{~g}$ of CNT with $0.26 \mathrm{~g}$ of $\mathrm{N}, \mathrm{S}, \mathrm{P}$, or B using the suitable precursor and labelled as indicated in Table 1. After mechanical mixing, the samples were subjected to a thermal treatment to promote the decomposition of the heteroatom precursor at the temperature indicated in Table 1.

Table 1. Modified carbon nanotubes (CNT) samples description.

\begin{tabular}{ccccc}
\hline Sample. & Description & Precursor Name & Formula & $\begin{array}{c}\text { Thermal Treatment } \\
\text { Temperature }\left({ }^{\circ} \mathrm{C}\right)\end{array}$ \\
\hline CNT-O & Pristine Material & - & - & - \\
CNT-N & N-doped CNTs & Melamine & $\mathrm{C}_{3} \mathrm{H}_{6} \mathrm{~N}_{6}$ & 600 \\
CNT-S & S-doped CNTs & Sodium thiosulfate & $\mathrm{Na}_{2} \mathrm{~S}_{2} \mathrm{O}_{3}$ & 900 \\
CNT-P & P-doped CNTs & Sodium dihydrogen phosphate & $\mathrm{NaH}_{2} \mathrm{PO}_{4}$ & 300 \\
CNT-B & B-doped CNTs & Boric acid & $\mathrm{H}_{3} \mathrm{BO}_{3}$ & 200 \\
\hline
\end{tabular}

\subsection{Characterization Techniques}

Pristine and modified CNTs were characterized to assess the main changes in their textural and surface properties promoted by the mechanothermal treatment. The textural characterization of the materials was based on the $\mathrm{N}_{2}$ adsorption-desorption isotherms, determined at $-196{ }^{\circ} \mathrm{C}$ in a Quantachrome NOVA 4200e multi-station apparatus (Quantachrome Instruments, Boynton Beach, FL, USA). The $\mathrm{C} / \mathrm{H} / \mathrm{N} / \mathrm{S}$ and $\mathrm{O}$ composition of the modified samples was determined by Elemental Analysis (EA) carried out on, respectively, vario MICRO cube and rapid OXY cube analyzers from Elemental GmbH, Langenselbold, Germany. X-ray Photoelectron Spectroscopy (XPS) has been used to assess the carbon surface composition. Analyses were performed using a Kratos AXIS Ultra HSA (Manchester, UK), with VISION software for data acquisition, CASAXPS software for data analysis. Thermogravimetric analysis (TGA) was carried out using an STA 409 PC/4/H Luxx Netzsch thermal analyzer (Selb, Germany). The morphology was observed by SEM/EDXS analysis using a FEI Quanta 400FEG ESEM/EDAX Genesis X4M instrument (Hillsboro, OR, USA). Additional details can be found elsewhere [47].

\subsection{Catalytic Wet Air Oxidation (CWAO) Experimental Procedure}

Experiments were carried out in a $160 \mathrm{~mL}$ 316-stainless steel high-pressure batch reactor Mod. 4564 (Parr Instruments, Moline, IL, USA), equipped with a stirring and temperature controller PARR 4842. Detailed reactor description may be found elsewhere [48]. Briefly, $75 \mathrm{~mL}$ of an oxalic acid aqueous solution (1000 $\left.\mathrm{mg} \mathrm{L}^{-1}\right)$ and $0.2 \mathrm{~g}$ of catalyst were placed into the reactor. The reactor was flushed with pure nitrogen until the complete removal of oxygen, and then pressurized with 5 bar of nitrogen and pre-heated up to $140{ }^{\circ} \mathrm{C}$ under continuous stirring (500 rpm). When the desired temperature was reached, pure air was injected to obtain a total pressure of 40 bar inside the reactor (corresponding to 7 bar of $\mathrm{O}_{2}$ partial pressure), this being considered time zero for the reaction $(t=0 \mathrm{~min})$. A non-catalytic oxidation run was carried out with air in the absence of catalyst, experiment denoted as WAO experiment. Reproducibility tests showed relative errors lower than $\pm 5 \%$. 


\subsection{Catalytic Wet Air Oxidation (CWAO) Analytical Techniques}

Liquid aliquots (around $1 \mathrm{~mL}$ ) were withdrawn from the reactor during reaction and centrifuged for further analysis. The samples were analysed by high-performance liquid chromatography (HPLC) with a Hitachi Elite LaChrom system equipped with a Diode Array Detector (L-2450). An Alltech OA-1000 column $(300 \mathrm{~mm} \times 6.5 \mathrm{~mm})$ working at room temperature in isocratic elution mode with a $\mathrm{H}_{2} \mathrm{SO}_{4}$ solution ( $5 \mathrm{mmol} \mathrm{L}^{-1}$ ) at a flow rate of $0.6 \mathrm{~cm}^{3} \mathrm{~min}^{-1}$ (as mobile phase) was used for oxalic acid identification and quantification (performed at $\lambda=210 \mathrm{~nm}$ ). Analyses were made using an injection volume of $15 \mu \mathrm{L}$. Calibration curves $\left(5-1200 \mathrm{mg} \mathrm{L}^{-1}\right)$ were made and linear responses were obtained in this range ( $R^{2}$ of calibration lines higher than 0.999$)$. All solutions and standard compounds were prepared with ultrapure water with a resistivity of $18.2 \mathrm{~m} \Omega$ at room temperature, obtained from a Milllipore Mili-Q system.

\section{Results and Discussion}

\subsection{Materials Characterization}

Textural properties of the ball milled CNT samples were evaluated by the $\mathrm{N}_{2}$ adsorption-desorption isotherms performed at $-196^{\circ} \mathrm{C}$, in order to evaluate the changes promoted by the mechanothermal treatment with the different heteroatoms. Figure 1 shows that $\mathrm{N}_{2}$ adsorption isotherms of all samples are of type II, accordingly to IUPAC classification [49]. For all samples the adsorption and desorption branches are not coincident, with a hysteresis loop being observed. The enlargement of the hysteresis is due to two contributions in the mesoporous character: the entanglement of nanotubes and the access to the inner cavity of the tubes [50]. The $\mathrm{N}_{2}$ adsorption isotherms at low relative pressure are very similar for the CNT-O, CNT-N, and CNT-S samples, in agreement with the small differences in the surface areas (Table 2); however, some differences were observed in the amount of $\mathrm{N}_{2}$ adsorbed at higher relative pressures (Figure 1).

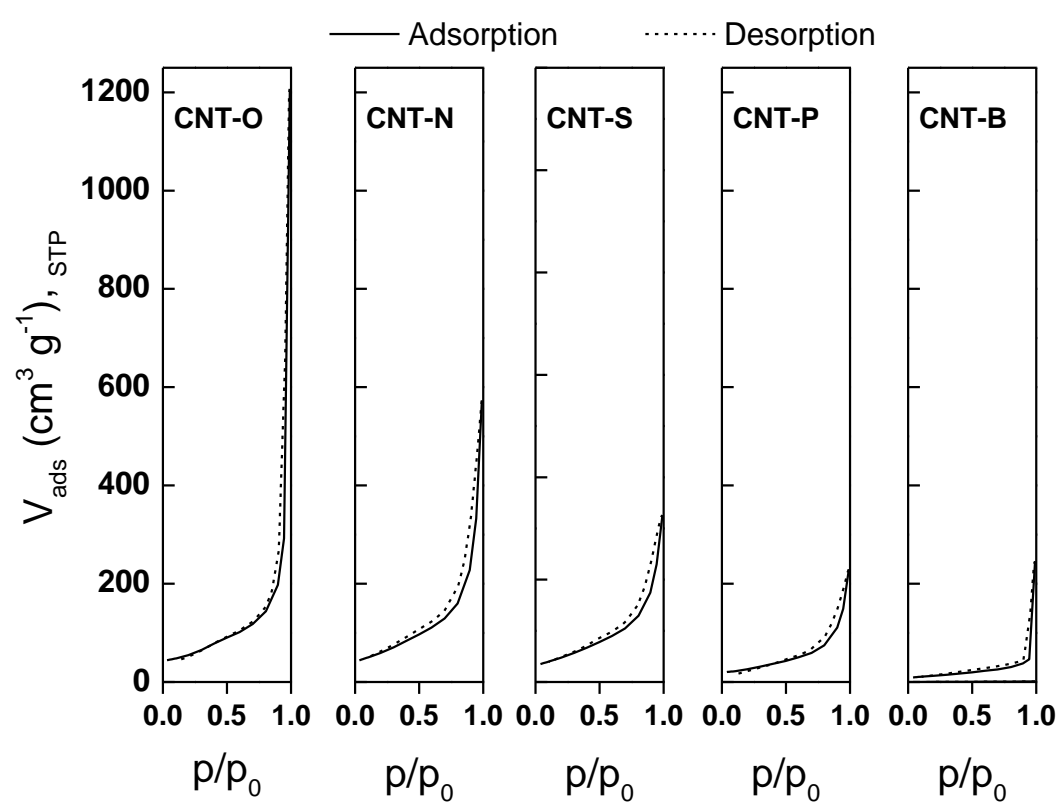

Figure 1. $\mathrm{N}_{2}$ adsorption-desorption isotherms at $-196^{\circ} \mathrm{C}$ for carbon nanotube materials.

The introduction of the precursors during the mechanical treatment promoted significant changes in the nanotube structures leading to the increase/decrease of the accessible surface area for $\mathrm{N}_{2}$ adsorption and decreasing the free-space between the tubes (evaluated by the total pore volume (Table 2)). The mechanical step reduced the entanglement of the CNTs, also leading to shorter CNTs by breaking up the tubes without affecting the tube diameters [46], therefore increasing the surface 
area of the carbon nanotubes. On the other hand, the introduction of N, S, P, and B-groups on the defects of the CNTs may block the access of $\mathrm{N}_{2}$ to the inner cavities and the presence of surface groups may also play an attractive effect between the tubes, leading to higher agglomeration of the material [38]. The addition of the nitrogen precursor leads to a small increase of the surface area comparing to the original sample $\left(192 \mathrm{~m}^{2} / \mathrm{g}\right)$; however, the addition of all the other precursors leads to a decrease of the surface area, this effect being more noticeable for samples CNT-B and CNT-P (45 and $93 \mathrm{~m}^{2} / \mathrm{g}$, respectively). This decrease is in line with the reduction in the carbon amount measured by elemental analysis (Table 3). The pore size distributions of all the samples, obtained by Non-Linear Density Function Theory (NLDFT) calculations, are presented in Figure 2. The ball milling treatment significantly modifies the pore size distribution. The pristine CNTs present a high number of large pores with a pore width larger than $16 \mathrm{~nm}$, whereas for the ball milled samples the number of larger pores is low. This change is mainly related to the ball milling treatment, since a significant reduction of the number of larger pores occurs when the pristine CNTs are ball milled without the presence of heteroatoms precursors [38]. However, sample CNT-B practically does not present pores with widths lower than $14 \mathrm{~nm}$, but there is a significant number of larger pores, in agreement with the small surface area observed.

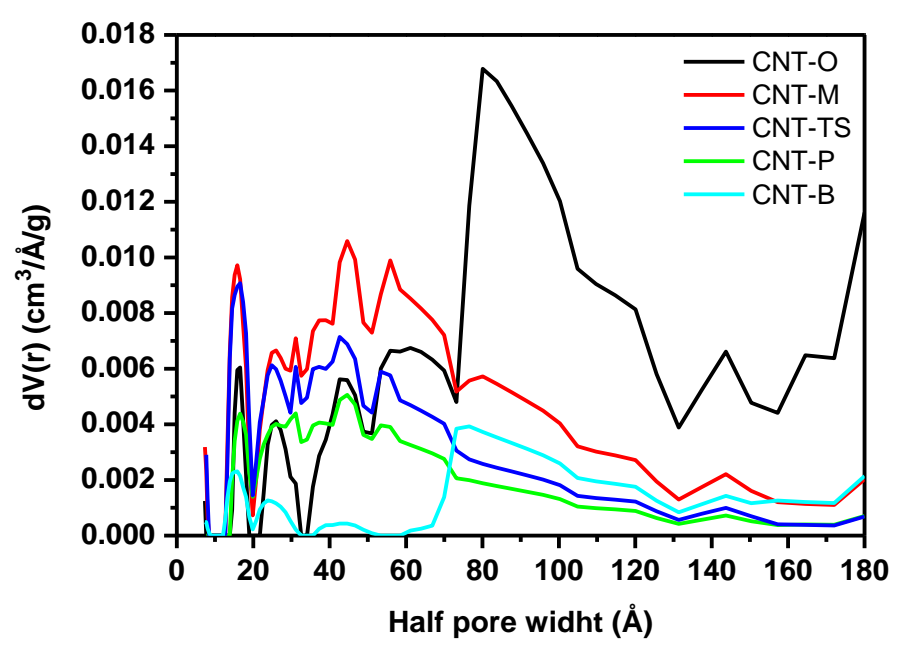

Figure 2. Pore size distributions obtained by Non-Linear Density Function Theory (NLDFT).

Table 2. Textural characterization of carbon nanotubes.

\begin{tabular}{ccc}
\hline Sample & $\mathbf{S}_{\text {BET }}\left(\mathbf{m}^{\mathbf{2}} \mathbf{g}^{-\mathbf{1}}\right)$ & $\mathbf{V}_{\mathbf{p}}\left(\mathbf{c m}^{\mathbf{3}} \mathbf{g}^{-\mathbf{1}}\right)$ \\
\hline CNT-O & 192 & 0.452 \\
CNT-N & 211 & 0.515 \\
CNT-S & 172 & 0.356 \\
CNT-P & 93 & 0.230 \\
CNT-B & 45 & 0.077 \\
\hline
\end{tabular}

Table 3. Bulk characterization by elemental analysis (EA) and surface chemistry characterization by X-ray photoelectron spectroscopy (XPS) and thermogravimetric (TGA) analyses of pristine and mechanothermally treated carbon nanotubes (CNT) samples.

\begin{tabular}{ccccccccccccc}
\hline \multirow{2}{*}{ Sample } & \multicolumn{4}{c}{ EA (\% wt.) } & \multicolumn{4}{c}{ XPS (\% wt.) } & \multicolumn{3}{c}{ TGA (\% wt.) } \\
\cline { 2 - 13 } & $\mathbf{C}$ & $\mathbf{N}$ & $\mathbf{H}$ & $\mathbf{S}$ & $\mathbf{O}$ & $\mathbf{C}$ & $\mathbf{O}$ & $\mathbf{S} / \mathbf{P} / \mathbf{B}$ & $\mathbf{N a}$ & Volatiles & C $_{\text {fixed }}$ & Ash \\
\hline CNT-O & 97.5 & 0.0 & 0.1 & 0.0 & 1.2 & & & & & 8.7 & 91.1 & 0.2 \\
CNT-N & 93.3 & 3.5 & 1.3 & 0.0 & 1.4 & & & & & 8.6 & 90.8 & 0.6 \\
CNT-S & 54.2 & 0.0 & 0.5 & 9.2 & 26.5 & 59.7 & 22.9 & $7.0(\mathrm{~S})$ & 10.4 & 29.3 & 21.3 & 49.4 \\
CNT-P & 41.4 & 0.0 & 0.3 & 0.0 & 28.0 & 78.6 & 13.5 & $4.5(\mathrm{P})$ & 3.4 & 8.2 & 39.5 & 52.3 \\
CNT-B & 33.7 & 0.0 & 2.6 & 0.0 & 44.1 & 31.4 & 49.9 & $18.7(\mathrm{~B})$ & & 5.3 & 32.0 & 62.7 \\
\hline
\end{tabular}


TGA analyses were performed in order to evaluate the thermal decomposition of the heteroatom precursors, to define the final thermal treatment temperature and to assess the functionalization degree of the samples. Figure 3 shows the TGA profiles of the samples mechanically treated with the selected precursors, before and after the thermal treatment. A detailed study with sample CNT-N was reported in a previous work [38]. Briefly, the thermal decomposition of melamine generates a significant weight loss (34\%) between 250 and $350^{\circ} \mathrm{C}$, mainly due to the release of $\mathrm{N}$-volatile compounds, followed by decomposition of the main chain and additional release of nitrogen volatiles up to $900{ }^{\circ} \mathrm{C}$ (less than $7 \%$ ), the total weight loss being close to the amount of melamine mixed with the CNTs [51]. After the thermal treatment at $600{ }^{\circ} \mathrm{C}$, the total weight loss in TGA until $900{ }^{\circ} \mathrm{C}$ is lower than $9 \%$, suggesting that the precursor has been previously decomposed. Regarding the TGA profile of sample CNT-S before thermal treatment, it is observed that sodium thiosulfate is poorly decomposed until $700{ }^{\circ} \mathrm{C}$; however, almost $50 \%$ of degradation is observed until $900{ }^{\circ} \mathrm{C}$, which corresponds to the weight percentage on the physical mixture $\mathrm{CNT}$ /precursor. For this reason, $900^{\circ} \mathrm{C}$ was chosen as the final temperature for the thermal treatment. Although the CNT-S sample had been treated at $900{ }^{\circ} \mathrm{C}$, the TGA profile after the thermal treatment still shows around $15 \%$ of weight loss between 700 and $900{ }^{\circ} \mathrm{C}$. The thermal degradation of sodium thiosulfate can form $\mathrm{Na}_{2} \mathrm{SO}_{3}$ and $\mathrm{S}$, which in the presence of oxygen may form $\mathrm{Na}_{2} \mathrm{SO}_{4}$ and $\mathrm{SO}_{2}[52,53]$. Therefore, it is expected that this sample would present some reactivity to oxygen after the thermal treatment and, if exposed to room conditions, it could explain its weight loss in the TGA at high temperatures. Sample CNT-P before the thermal treatment only presents a weight loss near $10 \%$ in the TGA temperature range studied. Two steps of decomposition can be observed around 200 and $250{ }^{\circ} \mathrm{C}$, probably due to the dehydration of sodium dihydrogen phosphate [54]. The sample remains stable after thermal treatment at $300{ }^{\circ} \mathrm{C}$, without additional weight loss in TGA. The thermal stability of the resulting residue suggests that phosphate could have been dehydrated to polyphosphates or metaphosphates [55]. In the TGA profiles of the CNT-B sample before and after thermal treatment the largest weight loss occurred until $200^{\circ} \mathrm{C}$, which is the reason why this temperature was chosen as the final temperature during the thermal treatment. Dehydration of boric acid is expected to occur above $150{ }^{\circ} \mathrm{C}$, leading to the formation of metaboric acid that can be further transformed to boron oxide $\left(\mathrm{B}_{2} \mathrm{O}_{3}\right)[56,57]$.

The mechanical treatment does not allow any functionalization of the carbon surface, as already reported in previous works $[46,47]$. It is during the thermal treatments that the decomposition of the precursors occurs, promoting the enrichment of the carbon surface with heteroatoms. Table 3 shows both bulk and surface characterization of the CNT samples after thermal treatments. Regarding the bulk composition in terms of CNHS, pristine CNTs revealed high purity with a carbon content of $97.5 \%$ and an oxygen content of $1.2 \%$. With the addition of the heteroatoms, the raw composition suffers from small to large changes, depending on the precursor used. The melamine treated sample only revealed the incorporation of $3.5 \%$ of nitrogen onto the CNT surface, as determined by EA. A strong decrease of the carbon content is observed in all other samples (around 50\%, being even higher in the case of the CNT-B sample). However, these decreases are in line with the introduction of other elements as $\mathrm{S} / \mathrm{P} / \mathrm{B} / \mathrm{O}$ and $\mathrm{Na}$ in the cases where sodium thiosulfate and sodium dihydrogen phosphate were used as precursors. EA revealed the incorporation of $9.2 \%$ of sulphur in the sample CNT-S, along with a significant increase of oxygen (26.5\%). The remaining composition (around $10 \%$ ) can be attributed to sodium from the precursor. These results are in agreement with the surface composition determined by XPS, where $10.4 \%$ of sodium has been detected. Considering that the initial weight percentage of $S$ on the physical mixture was $20.9 \%$, around $50 \%$ of the sulphur was kept on the carbon nanostructure by the applied approach. In the case of the CNT-P sample, bulk composition revealed the incorporation of a large amount of oxygen, accompanied by the introduction of $4.5 \%$ of $\mathrm{P}$ and also the retention of sodium. The most drastic change occurred with the sample CNT-B, where a large presence of B $(18.7 \%)$ accompanied by near $50 \%$ of oxygen (XPS) was observed. 


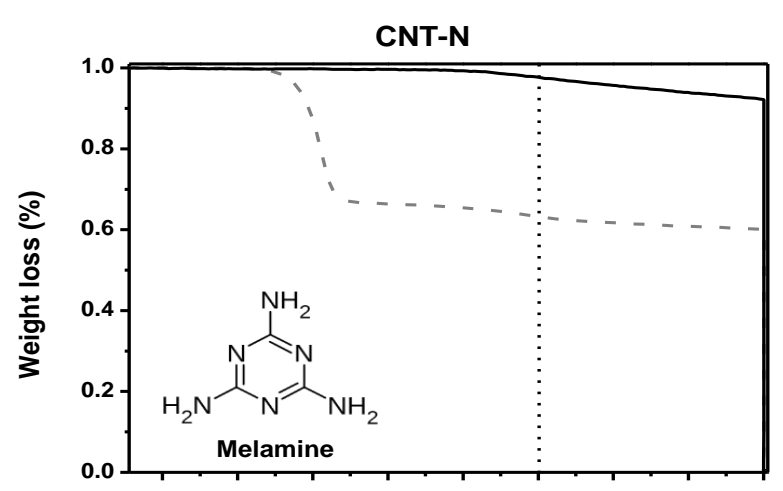

CNT-P

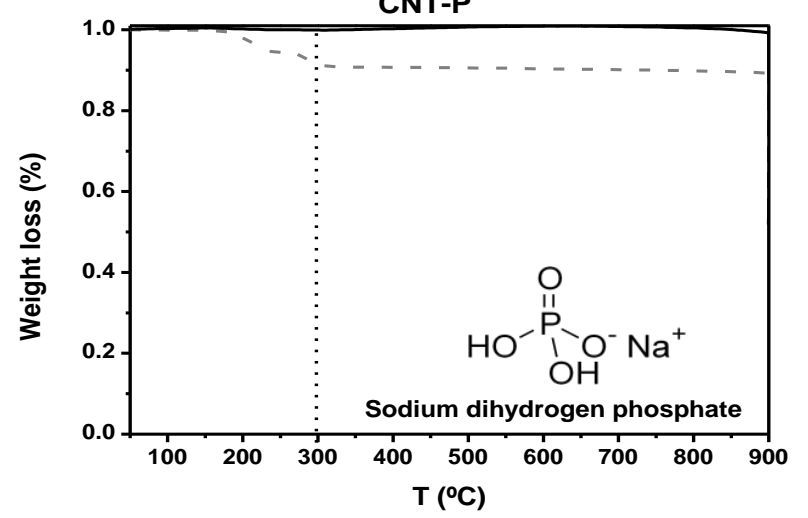

- - Without thermal treatment

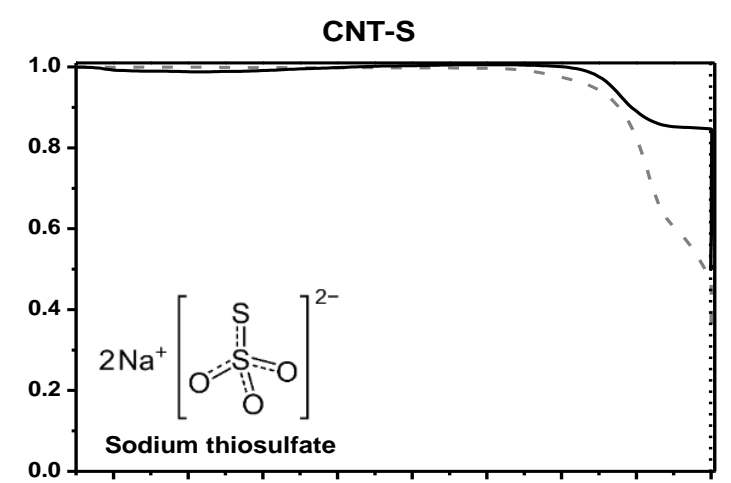

CNT-B

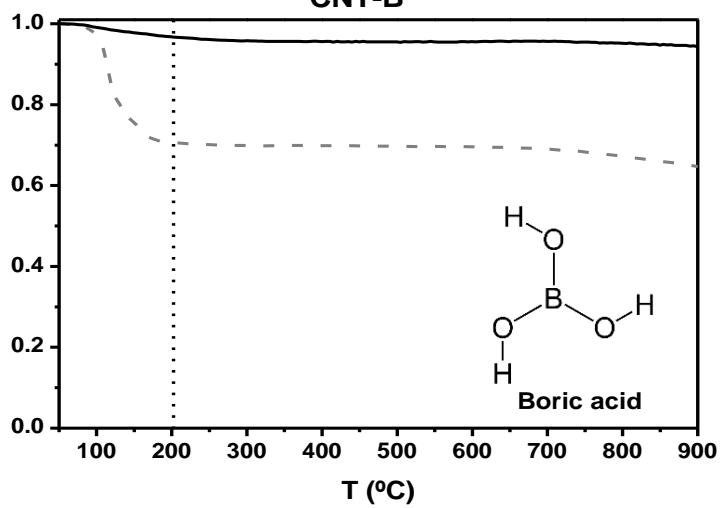

Figure 3. Thermogravimetric analysis (TGA) profiles under nitrogen of the modified carbon nanotube samples.

The nature of the N, S, P, and B-functionalities incorporated with the mechanothermal treatments was investigated using the corresponding spectra obtained by XPS (Figure 4). The asymmetric N1s spectrum of the sample CNT-N was deconvoluted in three peaks: quaternary nitrogen $(\mathrm{NQ}, \mathrm{B} . \mathrm{E} .=401.4 \pm 0.3 \mathrm{eV} ; 20 \%)$, pyrrole $(\mathrm{N} 5, \mathrm{~B} . \mathrm{E} .=400.1 \pm 0.2 \mathrm{eV}, 35 \%)$, and pyridinic $(\mathrm{N6}$, B.E. $=398.6 \pm 0.3 \mathrm{eV} ; 45 \%)$ structures, which are typically formed in carbon samples prepared above $550{ }^{\circ} \mathrm{C}$ [58]. Assumptions regarding the N1s spectrum fitting may be found elsewhere [38]. The S2p spectrum recorded for sample CNT-S was deconvoluted assuming that each of the 4 components has a $S 2 p_{3 / 2}$ and $2 p_{1 / 2}$ doublet separated by $1.18 \mathrm{eV}$ and with an intensity ratio of 2:1. The fitted $\mathrm{S}$ $2 \mathrm{p}_{3 / 2}$ peaks were ascribed to $\mathrm{Na}_{2} \mathrm{~S}_{2} \mathrm{O}_{3}(\mathrm{~S} 1, \mathrm{~B} . \mathrm{E} .=162.4 \mathrm{eV})$, elemental S $(\mathrm{S} 2, \mathrm{~B} . \mathrm{E} .=164.1 \mathrm{eV}), \mathrm{Na}_{2} \mathrm{SO}_{3}$ $(\mathrm{S} 3$, B.E. $=167.1 \mathrm{eV})$, and $\mathrm{Na}_{2} \mathrm{SO}_{4}(\mathrm{~S} 4, \mathrm{~B} . \mathrm{E} .=169.1 \mathrm{eV})$ [59]. The weak $\mathrm{S} 1$ component suggests that a small amount of precursor was not decomposed; however, the presence of the other three components suggests that the thermal degradation of sodium thiosulfate led to the formation of $\mathrm{Na}_{2} \mathrm{SO}_{3}$ and $\mathrm{S}$. In addition to the TGA results, the presence of the $\mathrm{Na}_{2} \mathrm{SO}_{4}$ species suggested that, even in the absence of oxygen during the thermal treatment, the sample became very reactive to oxygen, showing that some $\mathrm{Na}_{2} \mathrm{SO}_{3}$ may be converted into $\mathrm{Na}_{2} \mathrm{SO}_{4}[52,53]$. The P 2p spectrum of sample CNT-P has also been deconvoluted considering the $\mathrm{P} 2 \mathrm{p}_{3 / 2}$ and $2 \mathrm{p}_{1 / 2}$ doublet separated by $0.84 \mathrm{eV}$, with an intensity ratio of 2:1. A single peak was found at $134.6 \mathrm{eV}$, which is commonly attributed to phosphorous in the form of metaphosphates $\left(\mathrm{PO}_{3}{ }^{-}\right)$[59]. The absence of a peak corresponding to the binding energy at $133.2 \mathrm{eV}$ (typical of phosphate, $\left(\mathrm{PO}_{4}\right)^{3-}$ confirms that phosphate has suffered a thermal dehydration to metaphosphates, in agreement with the TGA results $[54,55]$. The B1s spectrum of the CNT-B sample shows a single peak at $193.0 \mathrm{eV}$, which is commonly assigned to boron oxide $\left(\mathrm{B}_{2} \mathrm{O}_{3}\right)$. Since this sample was treated at $200{ }^{\circ} \mathrm{C}$, and crystalline boron oxide has a melting point of $450{ }^{\circ} \mathrm{C}$, the sample CNT-B should be a physical mixture of $\mathrm{CNTs}$ and $\mathrm{B}_{2} \mathrm{O}_{3}$. This also explains the significant decrease of the 
surface area of this sample $\left(45 \mathrm{~m}^{2} \mathrm{~g}^{-1}\right)$, since $\mathrm{B}_{2} \mathrm{O}_{3}$ may be occupying the free space between the tubes or even covering some of them.
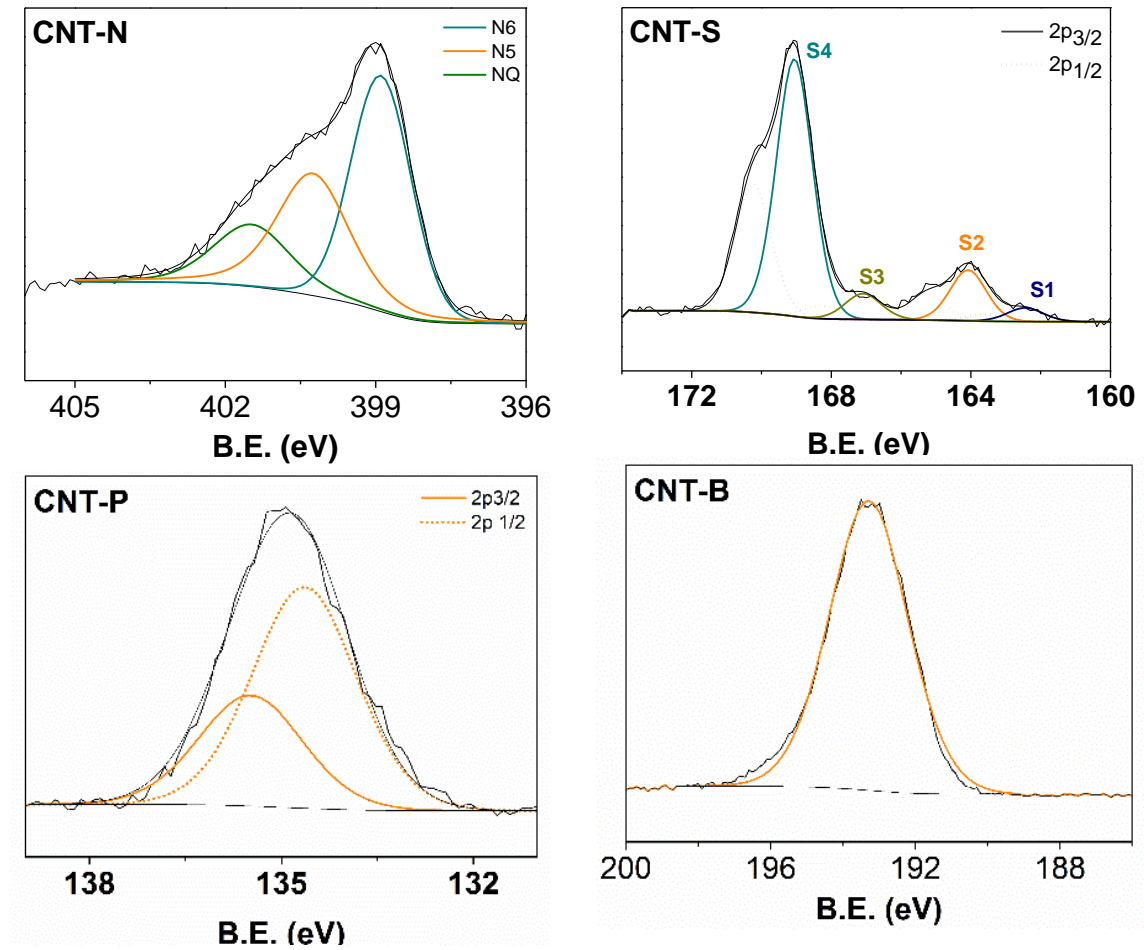

Figure 4. X-ray photoelectron spectroscopy (XPS) spectra recorded for samples carbon nanotube (CNT-N) (N1s), CNT-S (S2p), CNT-P (P2p) and CNT-B (B1s).

The surface morphology of the doped samples was assessed by SEM/EDS and compared with the pristine materials to confirm the enrichment of the carbon surface with heteroatoms. As can be seen in Figure 5, sample CNT-O displays highly entangled and twisted tubes. This entanglement was noticeably reduced after the ball-milling treatment, for all doped samples. Indeed, in previous work [46], it was observed (by TEM) that the ball-milling treatment is highly effective in disentangling and shortening the CNTs. Figure 5 shows that sample CNT-N presents a morphology similar to that of CNT-O, the main difference being the reduction in the entanglement. EDS analysis confirms the presence of $\mathrm{N}$-groups on the surface of the CNTs (Figure 5). The other doped samples exhibit a heterogeneous morphology, with regions where the heteroatom compounds have been deposited on the surface, identified by the different zones $\left(Z_{\mathrm{i}}\right)$. Sample CNT-P presents a more homogenous dispersion of the heteroatoms than CNT-S, but in both it is evident the existence of particles with planar faces suggest the presence of $\mathrm{P}$ and $\mathrm{S}$ in the form of metaphosphates $\left(\mathrm{PO}_{3}{ }^{-}\right)$and $\mathrm{Na}_{2} \mathrm{SO}_{3}$, respectively, since the EDS analysis reveals that the increase of each heteroatom is always accompanied by a corresponding increase in the amount of oxygen. These findings confirm the XPS and TGA results. Sample CNT-B presents a distinct morphology, in which the tubes seem to be in the form of dreadlocks. This observation could explain the low surface area of this sample (Table 1) due to the agglomeration of the tubes. The presence of boron in the form of boron oxide is confirmed in the surface of the nanotubes by the EDS analysis since oxygen is present in high amount when boron is identified. 

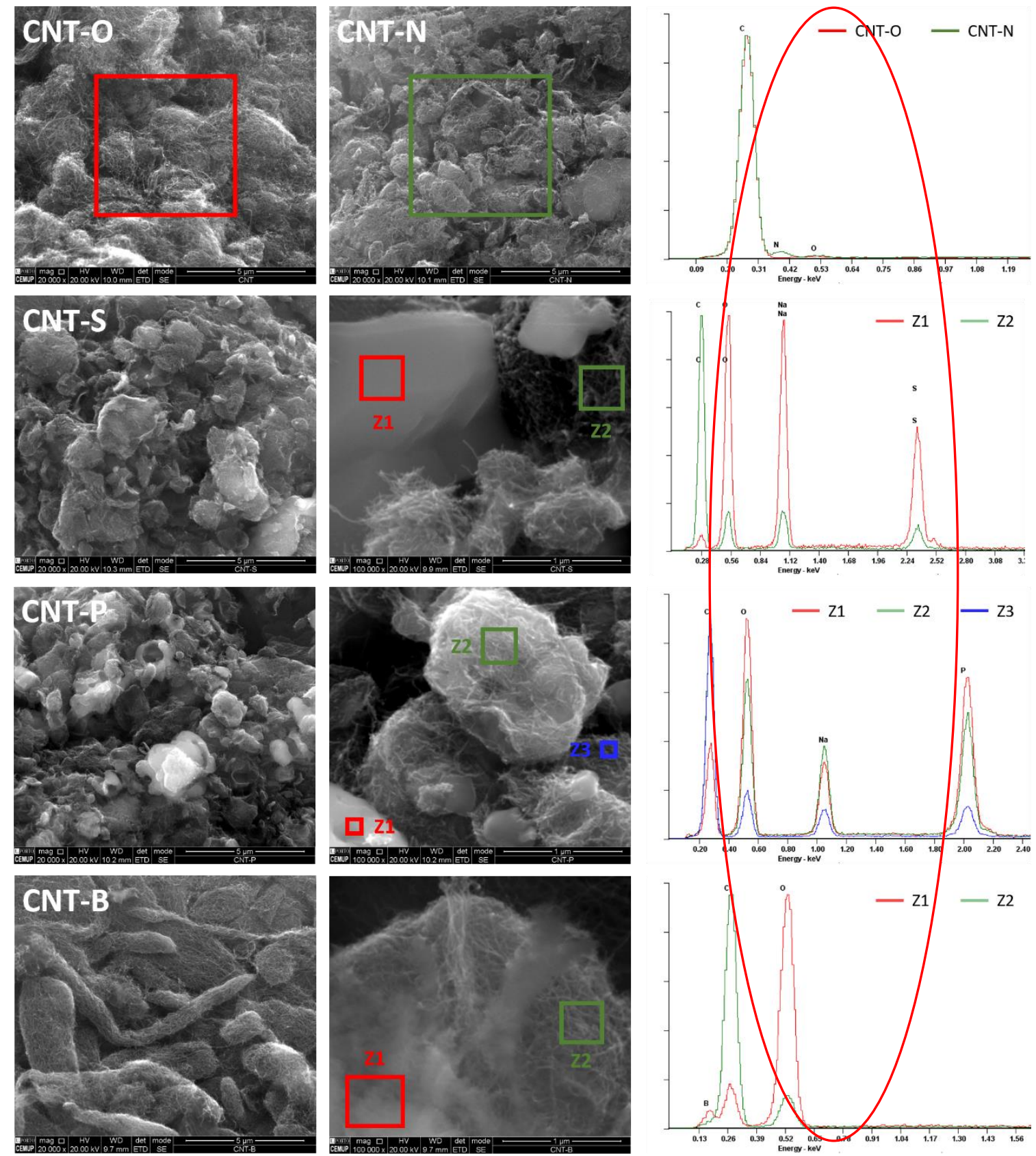

Figure 5. Scanning electron microscopy (SEM) images and Energy Dispersive X-ray Spectroscopy (EDS) analysis of the doped samples.

\subsection{Catalytic Activity in Catalytic Wet Air Oxidation (CWAO)}

The carbon materials doped with different heteroatoms were selected for catalytic tests in the oxidation of oxalic acid by CWAO. The materials were chosen with the aim to clarify their potential use as metal-free catalysts in the degradation of organic compounds by CWAO. Moreover, catalyst evaluation was outlined with the ambition to clarify the more adequate properties of carbon materials in the selected application. Oxalic acid was selected as a model compound to evaluate the process efficiency. It is representative of short chain carboxylic acids, which are typical refractory compounds appearing as end-products in the advanced oxidation processes. Figure 6 shows that oxalic acid is poorly oxidized under temperature and pressure employed in the absence of a catalyst, while CNT materials show high catalytic performance, with almost complete degradation of the model compound after $120 \mathrm{~min}$ of reaction, regardless of the sample tested (pristine or doped). 


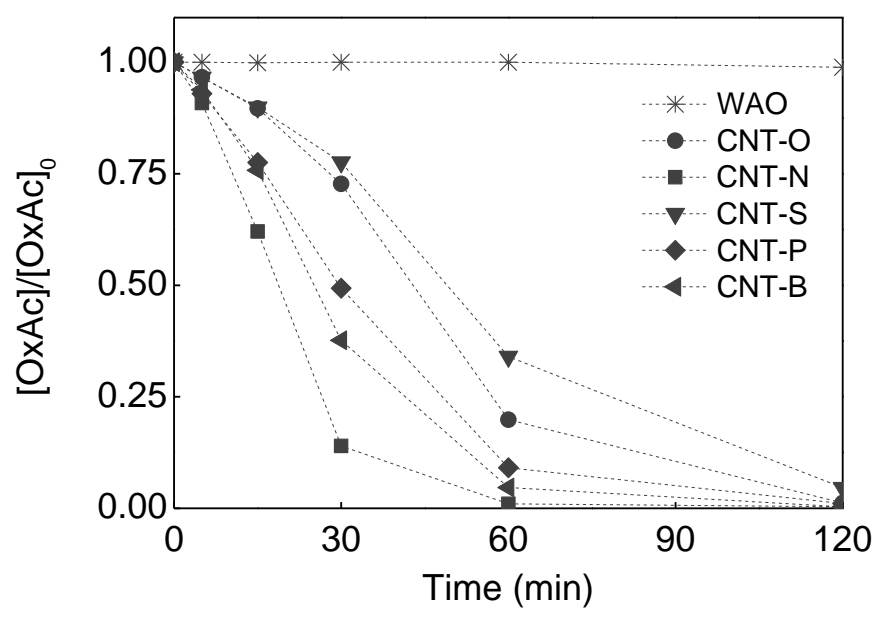

Figure 6. Evolution of normalized oxalic acid concentration at $140{ }^{\circ} \mathrm{C}$ and 40 bar of total pressure under non-catalytic conditions (WAO) and using doped carbon nanotube samples in catalytic wet air oxidation (CWAO).

Among the materials tested, the best performance was obtained with the sample CNT-N, which oxidized more than $85 \%$ of the initial oxalic acid concentration in $30 \mathrm{~min}$. For this same period, the CNT-B and CNT-P samples achieved $62 \%$ and $51 \%$ of oxalic acid degradation, respectively, while only $27 \%$ and $22 \%$ were obtained with CNT-O and CNT-S, respectively. These results indicate that incorporation of N, P, and B heteroatoms onto the commercial CNTs improved the intrinsic catalytic activity of the pristine materials, leading to a faster degradation of oxalic acid. In contrast, CNT-S exhibited the worst performance among the CNTs tested.

It is well accepted in the literature that the catalytic activity of carbon materials in oxidation reactions can be enhanced by adjustment of their textural and chemical properties [31]. Regarding the textural properties of the tested samples, no correlation was found between the catalytic activity and the surface area of these materials (Table 2). In fact, the doped samples with the highest surface areas and pore volume (CNT-N and CNT-S), presented the most opposite performances in the oxalic acid oxidation, while the samples with the lowest $\mathrm{S}_{\mathrm{BET}}$ (CNT-B and CNT-P) showed considerable catalytic activity. Hereupon, the heteroatoms present in the carbon sample must play an important role in the oxidation of oxalic acid. Despite all the reported studies regarding the use of carbon materials as catalysts in CWAO, the role of the surface chemistry in this reaction is still under debate. While the role of $\mathrm{O}-, \mathrm{N}-$, and S-containing groups have been extensively reported as alternative to the noble metal and rare earth oxide catalysts traditionally used in this process $[6,28,31,60-71]$, little attention has been given to the study of $\mathrm{P}$ and $\mathrm{B}$ in CWAO studies, contrary to what has happened in the field of electrochemistry [40,72-74]. The catalytic activity enhancement in the presence of $\mathrm{N}$-functionalities on CNTs was previously explained by the improvement of the electron interaction between carbon surface and oxygen [47]. Oxalic acid degradation pathway by CWAO is accepted to involve the adsorption of oxygen and oxalic acid on the carbon surface, oxygen being activated into reactive species that react with the adsorbed oxalic acid to produce carbon dioxide and water [48]. In the presence of N-groups with unpaired electrons, such as the pyridinic groups, there is an electron donation effect which may enhance the adsorption of oxygen, improving the surface oxidation mechanism [48]. Independently of the larger (nitrogen) or smaller (boron, phosphorous) electronegativity than carbon, it is believed that these heteroatoms break the electroneutrality of the graphitic structure [75]. Either the high electron-donating ability of $\mathrm{P}[75]$ and the intrinsic electron accepting nature of $\mathrm{B}$, may be translated into higher affinity to oxygen as compared to the pristine CNTs, improving the adsorption of oxygen [75] and the formation of the oxygen reactive species, which is expected to enhance the oxidation of oxalic acid [76]. A positive role of $\mathrm{P}-,_{-} \mathrm{B}-$, and N-heteroatoms in carbon blacks was also found by Diaz de Tuesta et al. [77] in a recent work on the catalytic wet peroxide oxidation of phenol. The doped-carbons 
yielded values of the kinetic rate constants of hydrogen peroxide degradation up to eight times larger than that obtained with the original carbon.

\section{Conclusions}

In the search for metal-free catalysts as cost-effective and eco-sustainable materials for replacing metal-based catalysts usually used in the CWAO process, the surface chemistry of carbon nanotubes was modified using a solvent-free methodology involving mechanical and thermal treatments in the presence of precursors of different heteroatoms $(\mathrm{N}, \mathrm{S}, \mathrm{B}, \mathrm{P})$. Although the methodology allows to incorporate different functional groups and large amounts of each heteroatom, in some cases it also promotes significant changes in the textural properties. An outstanding extent of oxidation of oxalic acid was achieved in the presence of the N-doped sample, followed by B- and P-doped samples, improving the intrinsic catalytic activity of the pristine material, whereas S-doped sample exhibited the worst performance. No correlation between the catalytic activity and the surface area of these materials was found, suggesting that the heteroatom incorporated into the carbon sample plays an important role in the degradation of oxalic acid, probably due to the high electron-donating ability of $\mathrm{P}$ and the intrinsic electron accepting nature of $\mathrm{B}$.

Author Contributions: O.S.G.P.S. and R.P.R. designed the experiments, prepared and characterized the doped CNTs. R.P.R. performed the CWAO catalytic tests. The manuscript was written by O.S.G.P.S. and R.P.R. with substantial supervision of J.J.M.O., M.F.R.P. and J.L.F.

Funding: This work is a result of: Project "AIProcMat@N2020_Advanced Industrial Processes and Materials for a Sustainable Northern Region of Portugal 2020", with the reference NORTE-01-0145-FEDER-000006, supported by Norte Portugal Regional Operational Programme (NORTE 2020), under the Portugal 2020 Partnership Agreement, through the European Regional Development Fund (ERDF); Associate Laboratory LSRE-LCM-UID/EQU/50020/2019—funded by national funds through FCT/MCTES (PIDDAC).

Acknowledgments: The authors are indebted to Carlos M. Sá (CEMUP) for assistance with XPS analyses.

Conflicts of Interest: The authors declare no conflict of interest.

\section{References}

1. Mishra, V.S.; Mahajani, V.V.; Joshi, J.B. Wet Air Oxidation. Ind. Eng. Chem. Res. 1995, 34, 2-48. [CrossRef]

2. Mantzavinos, D.; Sahibzada, M.; Livingston, A.G.; Metcalfe, I.S.; Hellgardt, K. Wastewater treatment: Wet air oxidation as a precursor to biological treatment. Catal. Today 1999, 53, 93-106. [CrossRef]

3. Kolaczkowski, S.T.; Plucinski, P.; Beltran, F.J.; Rivas, F.J.; McLurgh, D.B. Wet air oxidation: A review of process technologies and aspects in reactor design. Chem. Eng. J. 1999, 73, 143-160. [CrossRef]

4. Luck, F. Wet air oxidation: Past, present and future. Catal. Today 1999, 53, 81-91. [CrossRef]

5. Debellefontaine, H.; Foussard, J.N. Wet air oxidation for the treatment of industrial wastes. Chemical aspects, reactor design and industrial applications in Europe. Waste Manag. 25. [CrossRef]

6. Stüber, F.; Font, J.; Fortuny, A.; Bengoa, C.; Eftaxias, A.; Fabregat, A. Carbon materials and catalytic wet air oxidation of organic pollutants in wastewater. Top. Catal. 2005, 33, 3-50. [CrossRef]

7. Bhargava, S.K.; Tardio, J.; Prasad, J.; Foger, K.; Akolekar, D.B.; Grocott, S.C. Wet Oxidation and Catalytic Wet Oxidation. Ind. Eng. Chem. Res. 2006, 45, 1221-1258. [CrossRef]

8. Levec, J.; Pintar, A. Catalytic wet-air oxidation processes: A review. Catal. Today 2007, 124, $172-184$. [CrossRef]

9. Cybulski, A. Catalytic Wet Air Oxidation: Are Monolithic Catalysts and Reactors Feasible? Ind. Eng. Chem. Res. 2007, 46, 4007-4033. [CrossRef]

10. Silva, A.M.T.; Castelo-Branco, I.M.; Quinta-Ferreira, R.M.; Levec, J. Catalytic studies in wet oxidation of effluents from formaldehyde industry. Chem. Eng. Sci. 2003, 58, 963-970. [CrossRef]

11. Silva, A.M.T.; Quinta-Ferreira, R.M.; Levec, J. Catalytic and Noncatalytic Wet Oxidation of Formaldehyde. A Novel Kinetic Model. Ind. Eng. Chem. Res. 2003, 42, 5099-5108. [CrossRef]

12. Silva, A.M.T.; Marques, R.R.N.; Quinta-Ferreira, R.M. Catalysts based in cerium oxide for wet oxidation of acrylic acid in the prevention of environmental risks. Appl. Catal. B Environ. 2004, 47, 269-279. [CrossRef] 
13. Silva, A.M.T.; Oliveira, A.C.M.; Quinta-Ferreira, R.M. Catalytic wet oxidation of ethylene glycol: Kinetics of reaction on a Mn-Ce-O catalyst. Chem. Eng. Sci. 2004, 59, 5291-5299. [CrossRef]

14. Oliviero, L.; Barbier, J.; Duprez, D.; Wahyu, H.; Ponton, J.W.; Metcalfe, I.S.; Mantzavinos, D. Wet air oxidation of aqueous solutions of maleic acid over Ru/CeO2 catalysts. Appl. Catal. B Environ. 2001, 35, 1-12. [CrossRef]

15. Oliviero, L.; Wahyu, H.; Barbier, J., Jr.; Duprez, D.; Ponton, J.W.; Metcalfe, I.S.; Mantzavinos, D. Experimental and Predictive Approach for Determining Wet Air Oxidation Reaction Pathways in Synthetic Wastewaters. Chem. Eng. Res. Des. 2003, 81, 384-392. [CrossRef]

16. Quintanilla, A.; Casas, J.A.; Rodríguez, J.J. Catalytic wet air oxidation of phenol with modified activated carbons and Fe/activated carbon catalysts. Appl. Catal. B Environ. 2007, 76, 135-145. [CrossRef]

17. Quintanilla, A.; Menéndez, N.; Tornero, J.; Casas, J.A.; Rodríguez, J.J. Surface modification of carbon-supported iron catalyst during the wet air oxidation of phenol: Influence on activity, selectivity and stability. Appl. Catal. B Environ. 2008, 81, 105-114. [CrossRef]

18. Aguilar, C.; García, R.; Soto-Garrido, G.; Arriagada, R. Catalytic wet air oxidation of aqueous ammonia with activated carbon. Appl. Catal. B Environ. 2003, 46, 229-237. [CrossRef]

19. Eftaxias, A.; Font, J.; Fortuny, A.; Fabregat, A.; Stüber, F. Kinetics of phenol oxidation in a trickle bed reactor over active carbon catalyst. J. Chem. Technol. Biotechnol. 2005, 80, 677-687. [CrossRef]

20. Eftaxias, A.; Font, J.; Fortuny, A.; Fabregat, A.; Stüber, F. Catalytic wet air oxidation of phenol over active carbon catalyst: Global kinetic modelling using simulated annealing. Appl. Catal. B Environ. 2006, 67, 12-23. [CrossRef]

21. Santiago, M.; Stüber, F.; Fortuny, A.; Fabregat, A.; Font, J. Modified activated carbons for catalytic wet air oxidation of phenol. Carbon 2005, 43, 2134-2145. [CrossRef]

22. Suarez-Ojeda, M.E.; Stüber, F.; Fortuny, A.; Fabregat, A.; Carrera, J.; Font, J. Catalytic wet air oxidation of substituted phenols using activated carbon as catalyst. Appl. Catal. B Environ. 2005, 58, 105-114. [CrossRef]

23. Cordero, T.; Rodríguez-Mirasol, J.; Bedia, J.; Gomis, S.; Yustos, P.; García-Ochoa, F.; Santos, A. Activated carbon as catalyst in wet oxidation of phenol: Effect of the oxidation reaction on the catalyst properties and stability. Appl. Catal. B Environ. 2008, 81, 122-131. [CrossRef]

24. Quintanilla, A.; Casas, J.A.; Rodriguez, J.J. Hydrogen peroxide-promoted-CWAO of phenol with activated carbon. Appl. Catal. B Environ. 2010, 93, 339-345. [CrossRef]

25. Fortuny, A.; Font, J.; Fabregat, A. Wet air oxidation of phenol using active carbon as catalyst. Appl. Catal. B Environ. 1998, 19, 165-173. [CrossRef]

26. Rocha, R.P.; Sousa, J.P.S.; Silva, A.M.T.; Pereira, M.F.R.; Figueiredo, J.L. Catalytic activity and stability of multiwalled carbon nanotubes in catalytic wet air oxidation of oxalic acid: The role of the basic nature induced by the surface chemistry. Appl. Catal. B Environ. 2011, 104, 330-336. [CrossRef]

27. Sun, X.; Wang, R.; Su, D. Research progress in metal-free carbon-based catalysts. Chin. J. Catal. 2013, 34, 508-523. [CrossRef]

28. Rocha, R.P.; Silva, A.M.T.; Romero, S.M.M.; Pereira, M.F.R.; Figueiredo, J.L. The role of O- and S-containing surface groups on carbon nanotubes for the elimination of organic pollutants by catalytic wet air oxidation. Appl. Catal. B Environ. 2014, 147, 314-321. [CrossRef]

29. Duan, X.; Sun, H.; Wang, S. Metal-Free Carbocatalysis in Advanced Oxidation Reactions. Acc. Chem. Res. 2018, 51, 678-687. [CrossRef]

30. Bianco, A.; Cheng, H.-M.; Enoki, T.; Gogotsi, Y.; Hurt, R.H.; Koratkar, N.; Kyotani, T.; Monthioux, M.; Park, C.R.; Tascon, J.M.D.; et al. All in the graphene family-A recommended nomenclature for two-dimensional carbon materials. Carbon 2013, 65, 1-6. [CrossRef]

31. Figueiredo, J.L.; Pereira, M.F.R. The role of surface chemistry in catalysis with carbons. Catal. Today 2010, 150, 2-7. [CrossRef]

32. Figueiredo, J.L. Application of Nanocarbon Materials to Catalysis. In Nanotechnology in Catalysis; Wiley-VCH Verlag GmbH \& Co. KGaA: Weinheim, Germany, 2017; pp. 37-56.

33. Figueiredo, J.L.; Pereira, M.F.R. Carbon as Catalyst. In Carbon Materials for Catalysis; Serp, P., Figueiredo, J.L., Eds.; John Wiley \& Sons, Inc.: Hoboken, NJ, USA, 2009; pp. 177-217.

34. Hu, C.; Dai, L. Doping of Carbon Materials for Metal-Free Electrocatalysis. Adv. Mater. 2019, 31, 1804672. [CrossRef] [PubMed]

35. Suslick, K.S. Mechanochemistry and sonochemistry: Concluding remarks. Faraday Discuss. 2014, 170, 411-422. [CrossRef] 
36. Ma, P.C.; Wang, S.Q.; Kim, J.K.; Tang, B.Z. In-situ amino functionalization of carbon nanotubes using ball milling. J. Nanosci. Nanotechnol. 2009, 9, 749-753. [CrossRef] [PubMed]

37. Yuhua, X.; Hao, C.; Jia, Q.; Liming, D. Nitrogen-doped graphene by ball-milling graphite with melamine for energy conversion and storage. 2D Mater. 2015, 2, 044001. [CrossRef]

38. Soares, O.S.G.P.; Rocha, R.P.; Gonçalves, A.G.; Figueiredo, J.L.; Órfão, J.J.M.; Pereira, M.F.R. Easy method to prepare N-doped carbon nanotubes by ball milling. Carbon 2015, 91, 114-121. [CrossRef]

39. Jarrais, B.; Guedes, A.; Freire, C. Heteroatom-Doped Carbon Nanomaterials as Metal-Free Catalysts for the Reduction of 4-Nitrophenol. ChemistrySelect 2018, 3, 1737-1748. [CrossRef]

40. Hu, C.; Liu, D.; Xiao, Y.; Dai, L. Functionalization of graphene materials by heteroatom-doping for energy conversion and storage. Prog. Nat. Sci. Mater. Int. 2018, 28, 121-132. [CrossRef]

41. Jeon, I.-Y.; Choi, H.-J.; Jung, S.-M.; Seo, J.-M.; Kim, M.-J.; Dai, L.; Baek, J.-B. Large-Scale Production of Edge-Selectively Functionalized Graphene Nanoplatelets via Ball Milling and Their Use as Metal-Free Electrocatalysts for Oxygen Reduction Reaction. J. Am. Chem. Soc. 2013, 135, 1386-1393. [CrossRef] [PubMed]

42. Xu, J.; Shui, J.; Wang, J.; Wang, M.; Liu, H.-K.; Dou, S.X.; Jeon, I.-Y.; Seo, J.-M.; Baek, J.-B.; Dai, L. Sulfur-Graphene Nanostructured Cathodes via Ball-Milling for High-Performance Lithium-Sulfur Batteries. ACS Nano 2014, 8, 10920-10930. [CrossRef]

43. Woodman, R.H.; Klotz, B.R.; Dowding, R.J. Evaluation of a dry ball-milling technique as a method for mixing boron carbide and carbon nanotube powders. Ceram. Int. 2005, 31, 765-768. [CrossRef]

44. Xu, Z.; Zeng, Y.; Wang, L.; Li, N.; Chen, C.; Li, C.; Li, J.; Lv, H.; Kuang, L.; Tian, X. Nanoconfined phosphorus film coating on interconnected carbon nanotubes as ultrastable anodes for lithium ion batteries. J. Power Sources 2017, 356, 18-26. [CrossRef]

45. Soares, O.S.G.P.; Rocha, R.P.; Gonçalves, A.G.; Figueiredo, J.L.; Órfão, J.J.M.; Pereira, M.F.R. Highly active $\mathrm{N}$-doped carbon nanotubes prepared by an easy ball milling method for advanced oxidation processes. Appl. Catal. B Environ. 2016, 192, 296-303. [CrossRef]

46. Soares, O.S.G.P.; Goncalves, A.G.; Delgado, J.J.; Órfão, J.J.M.; Pereira, M.F.R. Modification of carbon nanotubes by ball-milling to be used as ozonation catalysts. Catal. Today 2015, 249, 199-203. [CrossRef]

47. Rocha, R.P.; Soares, O.S.G.P.; Gonçalves, A.G.; Órfão, J.J.M.; Pereira, M.F.R.; Figueiredo, J.L. Different methodologies for synthesis of nitrogen doped carbon nanotubes and their use in catalytic wet air oxidation. Appl. Catal. A Gen. 2017, 548, 62-70. [CrossRef]

48. Rocha, R.P.; Santos, D.F.M.; Soares, O.S.M.P.; Silva, A.M.T.; Pereira, M.F.R.; Figueiredo, J.L. Metal-Free Catalytic Wet Oxidation: From Powder to Structured Catalyst Using N-Doped Carbon Nanotubes. Top. Catal. 2018, 61, 1957-1966. [CrossRef]

49. Sing, K.S.W. Reporting physisorption data for gas/solid systems with special reference to the determination of surface area and porosity (Recommendations 1984). Pure Appl. Chem. 1985, 57, 603-619. [CrossRef]

50. Loiseau, A.; Launois-Bernede, P.; Petit, P.; Roche, S.; Salvetat, J.-P. (Eds.) Understanding Carbon Nanotubes from Basics to Applications Series: Lecture Notes in Physics; Springer-Verlag: Berlin/Heidelberg, Germany, 2006; Volume 677.

51. Seetapan, N.; Limparyoon, N.; Kiatkamjornwong, S. Effect of fire retardant on flammability of acrylamide and 2-acrylamido-2-methylpropane sodium sulfonate copolymer composites. Polym. Degrad. Stab. 2011, 96, 1927-1933. [CrossRef]

52. Piękoś, R.; Wesołowski, M.; Teodorczyk, J. Thermal Analysis of a Hydrated Silica-Sodium Thiosulfate-Sulfur System. J. Therm. Anal. Calorim. 2001, 66, 541. [CrossRef]

53. Sekkina, M.A.; El-Shereafy, E.-S.; Mashaly, A.; El-Ashry, M. $\gamma$-Pyrolysis of crystalline sodium thiosulphate penta hydrate. J. Radioanal. Nucl. Chem. 1998, 237, 113-119. [CrossRef]

54. de Jager, H.-J.; Prinsloo, L.C. The dehydration of phosphates monitored by DSC/TGA and in situ Raman spectroscopy. Thermochim. Acta 2001, 376, 187-196. [CrossRef]

55. Jinlong, N.; Zhenxi, Z.; Dazong, J. Investigation of phase evolution during the formation of calcium potassium sodium orthophosphate. Mater. Chem. Phys. 2003, 78, 308-312. [CrossRef]

56. Sevim, F.; Demir, F.; Bilen, M.; Okur, H. Kinetic analysis of thermal decomposition of boric acid from thermogravimetric data. Korean J. Chem. Eng. 2006, 23, 736-740. [CrossRef]

57. Pankajavalli, R.; Anthonysamy, S.; Ananthasivan, K.; Vasudeva Rao, P.R. Vapour pressure and standard enthalpy of sublimation of H3BO3. J. Nucl. Mater. 2007, 362, 128-131. [CrossRef] 
58. Boehm, H.-P. Catalytic Properties of Nitrogen-Containing Carbons. In Carbon Materials for Catalysis; Serp, P., Figueiredo, J.L., Eds.; John Wiley \& Sons, Inc.: Hoboken, NJ, USA, 2009; pp. 219-265.

59. Alexander, V.; Naumkin, A.K.-V.; Stephen, W.G.; Cedric, J.P. NIST Standard Reference Database 20, Version 3.4 (web version). Available online: https://srdata.nist.gov/xps/Version_his.aspx (accessed on 31 October 2018).

60. Soria-Sánchez, M.; Maroto-Valiente, A.; Álvarez-Rodríguez, J.; Muñoz-Andrés, V.; Rodríguez-Ramos, I.; Guerrero-Ruíz, A. Carbon nanostrutured materials as direct catalysts for phenol oxidation in aqueous phase. Appl. Catal. B Environ. 2011, 104, 101-109. [CrossRef]

61. Yang, S.; Li, X.; Zhu, W.; Wang, J.; Descorme, C. Catalytic activity, stability and structure of multi-walled carbon nanotubes in the wet air oxidation of phenol. Carbon 2008, 46, 445-452. [CrossRef]

62. Yang, S.; Zhu, W.; Li, X.; Wang, J.; Zhou, Y. Multi-walled carbon nanotubes (MWNTs) as an efficient catalyst for catalytic wet air oxidation of phenol. Catal. Commun. 2007, 8, 2059-2063. [CrossRef]

63. Yang, S.; Wang, X.; Yang, H.; Sun, Y.; Liu, Y. Influence of the different oxidation treatment on the performance of multi-walled carbon nanotubes in the catalytic wet air oxidation of phenol. J. Hazard. Mater. 2012, 233-234, 18-24. [CrossRef]

64. Wang, J.; Fu, W.; He, X.; Yang, S.; Zhu, W. Catalytic wet air oxidation of phenol with functionalized carbon materials as catalysts: Reaction mechanism and pathway. J. Environ. Sci. 2014, 26, 1741-1749. [CrossRef]

65. Yang, S.; Sun, Y.; Yang, H.; Wan, J. Catalytic wet air oxidation of phenol, nitrobenzene and aniline over the multi-walled carbon nanotubes (MWCNTs) as catalysts. Front. Environ. Sci. Eng. 2015, 9, 436-443. [CrossRef]

66. Restivo, J.; Rocha, R.P.; Silva, A.M.T.; Órfão, J.J.M.; Pereira, M.F.R.; Figueiredo, J.L. Catalytic performance of heteroatom-modified carbon nanotubes in advanced oxidation processes. Cuihua Xuebao Chin. J. Catal. 2014, 35, 896-905. [CrossRef]

67. Milone, C.; Shahul Hameed, A.R.; Piperopoulos, E.; Santangelo, S.; Lanza, M.; Galvagno, S. Catalytic Wet Air Oxidation of p-Coumaric Acid over Carbon Nanotubes and Activated Carbon. Ind. Eng. Chem. Res. 2011, 50, 9043-9053. [CrossRef]

68. Xing, B.; Chen, H.; Zhang, X. Efficient degradation of organic phosphorus in glyphosate wastewater by catalytic wet oxidation using modified activated carbon as a catalyst. Environ. Technol. 2018, 39, 749-758. [CrossRef] [PubMed]

69. Sousa, J.P.S.; Silva, A.M.T.; Pereira, M.F.R.; Figueiredo, J.L. Wet Air Oxidation of Aniline Using Carbon Foams and Fibers Enriched with Nitrogen. Sep. Sci. Technol. 2010, 45, 1546-1554. [CrossRef]

70. Rocha, R.P.; Restivo, J.; Sousa, J.P.S.; Órfão, J.J.M.; Pereira, M.F.R.; Figueiredo, J.L. Nitrogen-doped carbon xerogels as catalysts for advanced oxidation processes. Catal. Today 2015, 241, 73-79. [CrossRef]

71. Chen, H.; Yang, G.; Feng, Y.; Shi, C.; Xu, S.; Cao, W.; Zhang, X. Biodegradability enhancement of coking wastewater by catalytic wet air oxidation using aminated activated carbon as catalyst. Chem. Eng. J. 2012, 198-199, 45-51. [CrossRef]

72. Dong, F.; Cai, Y.; Liu, C.; Liu, J.; Qiao, J. Heteroatom (B, N and P) doped porous graphene foams for efficient oxygen reduction reaction electrocatalysis. Int. J. Hydrog. Energy 2018, 43, 12661-12670. [CrossRef]

73. He, W.; Xue, P.; Du, H.; Xu, L.; Pang, M.; Gao, X.; Yu, J.; Zhang, Z.; Huang, T. A facile method prepared nitrogen and boron doped carbon nano-tube based catalysts for oxygen reduction. Int. J. Hydrog. Energy 2017, 42, 4123-4132. [CrossRef]

74. Yan, Q.; Huang, G.-F.; Li, D.-F.; Zhang, M.; Pan, A.-L.; Huang, W.-Q. Facile synthesis and superior photocatalytic and electrocatalytic performances of porous B-doped g-C3N4 nanosheets. J. Mater. Sci. Technol. 2018, 34, 2515-2520. [CrossRef]

75. Serp, P.; Machado, B. CHAPTER 6 Doped Nanostructured Carbon Materials as Catalysts. In Nanostructured Carbon Materials for Catalysis; The Royal Society of Chemistry: London, UK, 2015.

76. Serp, P.; Machado, B. CHAPTER 5 Nanostructured Carbon Materials as Catalysts. In Nanostructured Carbon Materials for Catalysis; The Royal Society of Chemistry: London, UK, 2015.

77. Diaz de Tuesta, J.L.; Quintanilla, A.; Casas, J.A.; Rodriguez, J.J. P-, B- and N-doped carbon black for the catalytic wet peroxide oxidation of phenol: Activity, stability and kinetic studies. Catal. Commun. 2017, 102, 131-135. [CrossRef]

(C) 2019 by the authors. Licensee MDPI, Basel, Switzerland. This article is an open access article distributed under the terms and conditions of the Creative Commons Attribution (CC BY) license (http://creativecommons.org/licenses/by/4.0/). 